\title{
ERASing THE Social From Social Science: The Intellectual Costs of BOUNDARY-WORK AND THE CANADIAN Institute of Health Research
}

\author{
Katelin Albert
}

Abstract. In 2009, Canadian social science research funding underwent a transition. Social science health-research was shifted from the Social Science and Humanities Research Council (SSHRC) to the Canadian Institute of Health Research (CIHR), an agency previously dominated by natural and medical science. This paper examines the role of health-research funding structures in legitimizing and/or delimiting what counts as 'good' social science health research. Engaging Gieryn's (1983) notion of 'boundary-work' and interviews with qualitative social science graduate students, it investigates how applicants developed proposals for CIHR. Findings show that despite claiming to be interdisciplinary, the practical mechanisms through which CIHR funding is distributed reinforce rigid boundaries of what counts as legitimate health research. These boundaries are reinforced by applicants who felt pressure to prioritize what they perceived was what funders wanted (accommodating natural-science research culture), resulting in erased, elided, and disguised social science theories and methods common for 'good social science.'

Keywords: Interdisciplinary; boundary-work; Canadian Institute of Health Research; research funding; knowledge production; epistemic cultures

Résumé. En 2009, le financement de la recherche sociale au Canada a subi une période de transition au niveau de sa structure. Dorénavant, la recherche sociale en santé, qui auparavant était éligible au financement du Conseil de recherches en sciences humaines (CRSH), est admissible qu'au financement des Instituts en recherche en santé du Canada (IRSC), un organisme initialement dominé par les sciences naturelles et médicales. Cette recherche explore le rôle des structures de financement des recherches en santé dans la légitimation et/ou la délimitation de ce qui est considéré comme de la 'bonne' recherche en sciences sociales. $\mathrm{Me}$ basant sur la notion de 'boundary-work', formulé par Gieryn (1983), et sur des entrevues réalisées auprès d'étudiants en recherche qualitative des cycles supérieurs en sciences sociales, j'examine la manière dont les candidats ont développé 
leur projet de recherche pour les IRSC. Les résultats démontrent que bien qu'ils se présentent comme interdisciplinaires, les mécanismes pratiques à travers lesquels les IRSC distribuent leur financement renforcent la délimitation de ce qui est considéré comme de la recherche légitime en sciences sociales. Cette délimitation est renforcée par les candidats qui se sentaient obligés de prioriser ce qui leur paraissait être les demandes des bailleurs de fonds (répondre à la culture de recherche en sciences naturelles), se traduisant par l'effacement, l'omission, et le déguisement des théories et méthodes en sciences sociales courants dans de 'bonnes recherches en sciences sociales.'

\section{INTRODUCTION}

In 2000, the Canadian Institute of Health Research (CIHR) was established to encourage interdisciplinary health research and in 2009, all funding for social science health research shifted from the Social Science and Humanities Research Council (SSHRC) to CIHR. The following year, the Canadian Institute of Health Research held a grants-crafting workshop for social scientists. ${ }^{1}$ The workshop, which took place in a large auditorium at Congress 2010 for the Social Sciences and Humanities, involved a PowerPoint presentation that conveyed the following guidelines: CIHR encourages team projects over individual projects, applied research projects, and the use of scientific language. During the question and answer period, many audience members raised the concern that the philosophies and traditions of their research did not seem appropriate for CIHR. They worried over the practicality of creating an application that would 'match' CIHR's goals and style while maintaining the unique methods and contributions of social science. In response to these concerns, the workshop's speaker provided the following suggestion:

Imagine I travelled to a foreign country and refused to speak the native language of where I was. How could I ask for help? How could I ask for food? How could I say anything? If I wanted something, I would have to learn the language. I would have to follow their rules. I would have to accommodate them... Just use our language; it's not that bad. [recorded from memory after the presentation]

Scholars typically conduct their research within the distinct organizational structures of university departments and disciplinary boundaries

1. The observations in this paragraph are my own and based on my attending this workshop. I did not individually speak with any of the other workshop attendees about their thoughts or opinions. 
(Abbott 2001). Disciplines are highly specialized, with their own particular language, theories, and methods. Yet, interdisciplinary studies and institutes continue to grow, and it is becoming increasingly common to argue that research must occur outside traditional disciplinary boundaries. Health research, which has historically been dominated by the biological and medical sciences, is now taken up by social scientists who can provide richness and complexity to the field.

Despite the scholarly benefits of interdisciplinarity, such as pursuit of complex research questions, there are barriers to interdisciplinary work (Jacobs and Frickel 2009). Many scholars have questioned what is meant by 'interdisciplinary' and how interdisciplinary projects occur (Apostel, Berger, Briggs and Michaud 1972; Frodeman, Thompson and Mitcham 2010). The conversation surrounding the practicalities, benefits, and disadvantages of interdisciplinarity are part of an ongoing 'interdisciplinary debate.'

This research contributes to the debate by considering the microlevel processes through which the boundaries that separate 'scientific' and 'non-scientific' research projects are negotiated in the process of becoming 'more interdisciplinary.' My particular concern is with the intellectual costs of boundary work in health research, where medical and natural science models have historically dominated funding priorities and where there is a trend toward greater interdisciplinarity.

This research focuses on the Canadian Institute of Health Research as an interdisciplinary funding organization to illuminate the ways in which social scientists at the graduate level (junior social scientists, hereafter) attempt to bridge the boundaries between qualitative social science and biomedical science. I draw on Gieryn's (1983) concept of 'boundary-work,' which addresses the power struggles between scientific communities in the process of delineating science from non-science. This paper thus identifies moments of boundary-work when demarcations of scientific fields of knowledge are produced, challenged, or reinforced. This focus exposes the intellectual costs incurred when researchers attempt to cross the boundary between two disciplines - specifically, when qualitative social science researchers feel tremendous pressure to erase the social aspects of their work to align with what they perceive to be CIHR's epistemic culture. These costs include the erasure of critical strategies and theory, creative methodological approaches, and feminism from social science research.

To do this, I explicate the application process for junior social scientists producing qualitative social scientific research proposals that attempt to meet the internationally accepted standards of scientific excellence embedded in natural-science research culture. Doing so illumin- 
ates how specification and adjudication of funding requirements influence negotiations between funding applicants and the people who advise their applications.

My analysis of CIHR's funding process, coupled with seven in-depth qualitative interviews with applicants, exposes evidence of boundary accommodation during the development of CIHR funding applications. Applicants modified their research projects to meet what they perceived as legitimate scientific objectives at the expense of their personal or disciplinary research aspirations. Applicants worked to comply with the established, yet ambiguous, boundary between social science and natural science. In doing so, they reinforced and reproduced this boundary. To conclude the paper, I argue that to realize the benefits of interdisciplinary research, more attention must be paid to the institutional and cultural dominance of traditional/positivist/deductive scientific methods. This dominance remains deeply embedded, even when interdisciplinarity is promised at the macro-level through restructuring of national funding. I suggest that researchers and funders should broaden the evaluative boundaries of what counts as 'good' health research by better integrating and legitimizing alternative forms of knowledge production.

\section{BaCkground ANd Context}

Established in Canada in 2000, CIHR replaced two federal research agencies, the National Health Research and Development Program and the Medical Research Council. It was developed as a model to emphasize excellence, promote interdisciplinary work, partnerships, priority setting, and solutions-focused research. This interdisciplinary work was intended to involve collaborative approaches to health research across biomedical, clinical, and health systems and services to determine the social, cultural, and environmental factors that affect the health of populations (CIHR 2000). Because of the establishment of CIHR, by 2009, social science research related to health was no longer fundable by a granting agency dedicated to social science and humanities research, but instead fell under the interdisciplinary umbrella of CIHR.

CIHR's goal of joining social science and science is not unique to the Canadian case. Albert, Laberge, and Hodges (2009) compare the development of CIHR to the United States' National Institute of Health (NIH), an organization that reorganized its budget to develop methodologies that enable interdisciplinary work in behavioural and social science health research (see also Bachrach and Abeles 2004; NIH-National Institute of Health 2007). A central phrase in CIHR's mandate identi- 
fies the agency's interest in research that will "excel, according to internationally accepted standards of scientific excellence" (CIHR 2000, 3). This mandate is part of an ongoing political debate among scientists, social scientists, research agencies, and politicians (see Solovey 2004 on SSRC).

Researching CIHR, De Villiers (2005) and Morse (2006) investigate social scientists who conduct health research and suggest that the "current attempts to integrate the social sciences into this domain are encountering significant difficulties and resistance," likely, in part, "because social sciences must integrate themselves into a domain where the dominant research paradigm is experimental" (in Albert, Laberge, Hodges, Regehr, and Lingard 2008, 2521). CIHR comprises thirteen institutes that are open to all applicants. No institute, however, is specifically designated for social science research. Further, of CIHR's thirteen institutes, only one is concerned with population health, the research area most commonly addressed by social science applications. This indicates an uneven preference for biomedical research and biomedical conceptions of health and health issues. As Raphael (2011) observes, "even this institute, [population health], provides most of its funding to traditional epidemiologically oriented, rather than critical, social science analysis of health issues" (224).

Within CIHR, social scientists have little representation on peer review committees (PRC) that would likely evaluate social science applications. For example, the majority of committee members in the Aboriginal health PRC and population health PRC come from medicine, nursing, and epidemiology backgrounds (CIHR 2013). The Fall 2009 Aboriginal health PRC had eight members, seven of whom were from medicine, nursing, or endocrinology. The eighth member was from women and gender studies. The Fall 2009 population health PRC was weighted similarly. Seven members were from the faculty of medicine, several of whom were epidemiologists; one was a physicist who specialized in mathematical modelling; one was from the department of geography; and only one member was a senior social scientist. Moving forward, in 2010, 2011, and 2012 the committees for Aboriginal and population health begin to include more social scientists, although the composition still favours medicine, nursing, and epidemiology backgrounds.

Across the biomedical and social sciences, there are variations in the definition of health. Albert et al. (2008) state that differences in definitions may produce an 'epistemological and cultural 'clash' between the biomedical sciences (mostly experimental and favouring a biological view of health) and the social sciences (mostly non-experimental and favouring a more holistic view of health)" (2521). For the medical sci- 
ences, health is considered as a "physiological and individual phenomenon, with social factors given only secondary considerations" (Albert et al. 2008, 2521). Moreover, the medical sciences have an organic vision of populations, leading to particular interventions and policy implications that differ from those developed by social scientists (Bernier 2005). The biomedical and natural science-dominated composition of CIHR's PRCs suggests that CIHR's epistemological framework favours research that adheres to the hegemonic paradigm of experimental science.

\section{Interdisciplinarity: Where epistemic cultures collide}

In recent years, interdisciplinarity has been encouraged and even institutionalized in the strategic plans of universities and research organizations (Coulter 2008). From a practical perspective, interdisciplinary research is seen as a way to stretch academic resources by generating grant support, improving efficiencies, and focusing diverse research energies on a common effort (Brint 2005). Interdisciplinary collaboration is also believed to be trainable: in 1997, the US National Science Foundation (NSF) invested in the Integrative Graduate Education and Research Traineeship (IGERT) program designed to train students in interdisciplinary collaboration (Coulter 2008). ${ }^{2}$

Canadian qualitative social scientists face challenges as they move their research into the health field because the epistemic culture of medical research is very different from that of the social sciences. Many hurdles, cultural boundaries, and rites of passage accompany a move into the more conservative health sector (Bernier 2005). Training in the health research sector differs from the training received by social science doctoral students who are often encouraged to think independently and

2. There is quite a lot of literature on 'best practices' for interdisciplinary work and collaboration that is beyond the scope of this paper. See Lyall, Bruce, Tait, and Meagher's (2011) seminal text, Interdisciplinary Research Journeys, which offers advice for researchers and research managers on designing, facilitating, implementing, and sustaining interdisciplinary projects. They argue that institutional leaders play a key role in facilitating effective and harmonious interdisciplinary research. They also recognize that "disciplines place boundaries around bodies of knowledge," which can make interdisciplinary evaluation of quality difficult (193). Peer review and evaluation are essential components of interdisciplinary research and discipline specific evaluation criteria are not appropriate for interdisciplinary initiatives. O'Rourke, Crowley, Eigenbrode, and Wulfhorst's (2014) Enhancing Communication and Collaboration in Interdisciplinary Research offers a collection of valuable literature on communication and collaboration addressed to a broad audience. 
outside "established frameworks" (125). For Bernier, the interdisciplinary integration of disciplines is a form of cultural integration.

Interdisciplinary studies are distinct from multidisciplinary and transdisciplinary endeavours. They occur when "insights into a common problem from two disciplines $(\mathrm{A}+\mathrm{B})$ are integrated to construct a more comprehensive understanding" (Repko 2012, 19). This is distinct from research endeavours that engage in "bridge building" where "tools" are borrowed from other disciplines (Repko 2012, 19-27). Interdisciplinary research is not simply learning to be "bilingual" in foreign disciplines/ languages because bilinguality implies speaking one language at a time. Instead, in interdisciplinarity, the goal is "drawing different insights from each language and integrating them" (Repko 2012, 28).

Scholars supporting interdisciplinary work emphasize a reduction of disciplinary boundaries (Repko 2012) and promote work that develops from crosscutting themes rather than being overly categorical (Braithwaite 2005). For example, drawing on Burawoy's arguments for public sociology and the resistance of "mediocre disciplinary methods," Braithwaite (2005) states, "we can resist the way disciplines enforce the methodological orthodoxy of their own tradition, instead of training students to scan the social sciences for the best method for a particular problem" (347). In a similar way, Szostak (2012) emphasizes that "disciplinarians necessarily ignore competing theories or methods, and they also ignore related phenomena that might cast an important light on the issues addressed by the discipline" (4, original emphasis). ${ }^{3}$ Some advocates of interdisciplinary research emphasize the need for "boundary crossing," or a "process of moving across knowledge formations for the purpose of achieving an enlarged understanding" (26). Others, such as Hacking (2004), argue that interdisciplinarity does not mean "breaking down disciplinary boundaries," but instead involves the application of disciplines in "different directions" (194). Certain methods, however, are more easily transported across disciplinary boundaries. For example, statistical procedures like the Cox regression may be more easily applied in different disciplines (Jacobs 2009), which could lead to the prioritization of particular methods during interdisciplinary collaboration.

3. Defending disciplines, but not necessarily rejecting interdisciplinarity, Jacobs (2014) states that "disciplines have overstated their complaints and underappreciated the value of interconnected systems of academic disciplines" (3). He argues that significant ideas result from discipline-oriented work and that disciplines do communicate. 
Moreover, the social sciences have produced many successful interdisciplinary endeavours, including women's studies, gender studies, ethnic studies, indigenous studies, liberal studies, and queer studies. The merging of disciplines has created new forms of critical knowledge that challenge mainstream ideologies. The measure of success, however, varies depending on organizational goals.

While popular, interdisciplinary work can be rife with pitfalls and barriers (Jacobs 2014, Jacobs and Frickel 2009), especially in collaborations among the social and natural or biomedical sciences. Prainsack, Svendsen, Kock and Ehrich (2010) argue that research agencies encourage the collaboration of science with other disciplines such that social science enters into existing bio-scientific settings or adopts dominant practices and views of scientific excellence. This produces scholarly specializations that are called interdisciplinary but that in fact depend on "the presence of strong disciplines" (Jacob 2009). These scholars have asked us to rethink interdisciplinarity (Heintz and Origgi 2004) and to reconsider the processes through which interdisciplinary projects actually occur (Apostel, Berger, Briggs and Michaud 1972).

Health research, which has historically been dominated by biological and medical sciences, is now also undertaken by social scientists, many of whom want to contribute to an interdisciplinary conversation (Seddon 2013). While interdisciplinary institutions such as CIHR may attempt to dissolve the boundaries between science and 'other pursuits of knowledge,' these boundaries remain very real for social scientists moving into the health field. Tensions arise when epistemological and methodological traditions must be filtered through an interdisciplinary institute's dominant research culture (Albert et al. 2009). Many qualitative social science researchers face daunting challenges as they attempt to stake out a position as valid knowledge producers alongside researchers who work within experimental, quantitative, and biological epistemic cultures.

Bourdieu (2004) argues that each discipline has its own 'disciplinary habitus,' which affects how practitioners conduct their research. Knorr-Cetina compares research in molecular biology to experiments in high-energy physics and concludes that 'epistemic cultures' vary widely even within the natural sciences (1999). These concepts highlight social science and medical researchers as "social actors who are members of scientific communities and therefore embedded in a community-specific (nonetheless porous) web of significations" (Albert et al. 2009,173). Lamont's (2009) work on peer-review committees exposes differences in how professors think based on their "cultures of evaluation," rooted in academic background. Literature and anthropology professors tend to emphasize theoretical elegance, and economics and political science 
professors stress logical rigor in their evaluations. While Lamont optimistically concludes that peer-review committees are doing their best in the face of vast differences, her study exposes divides even among social scientists. These differences are intensified when looking at the relationship between social science and natural science.

Social scientists have long debated what constitutes social science, what distinguishes it from natural science, and whether it has a place within natural science research agendas (Solovey 2004). ${ }^{4}$ This historical debate is still alive in a contemporary context as interdisciplinarity is forced and attempted, as natural and social sciences continue to join research agendas, and as researchers compete for scarce resources. Researchers continue to grapple with the question of what knowledge production(s) counts as legitimate as they navigate epistemological and interdisciplinary terrain. Gaps in researchers' perceptions of legitimate knowledge can result in 'non-knowledge,' 'negative knowledge' (Gross 2007), or what Hess (2007) calls 'undone science,' where particular research agendas or areas are left unfunded, incomplete, and ignored.

My investigation into the inclusion of qualitative social science in CIHR is part of a multi-national and historical conversation on what counts as credible knowledge production. While the existing literature demonstrates that funding conditions shape knowledge production and the everyday work of graduate students and faculty (Carrier 2010), still missing is an explanation of how knowledge and science are constructed for funding through disciplinary politics and at what intellectual costs. For instance, scholars have shown that funding conditions are shaped by economic and institutional restructuring (Subramaniam, Perrucci and Whitlock 2014; Laudel 2014), and that this, in turn, changes academic values (Etzkowitz 1998) and research practices (Morris 2000). Subramaniam et al. (2014) argue, "structural constraints, specifically within sociology, are enabling the emergence of narrower perspectives and eroding former professional norms as individual decisions aggregate, unintentionally, to constitute a more competitive discipline with narrower definitions of productivity and quality" (411). However, this

4. In his historical research on the National Science Foundation and the Social Science Research Council in the U.S., Solovey (2004) highlights social science's "problematic status" in national debates about what scientific research can contribute to the United States. Social science was seen as at odds with the scientific demand for objective, value-free, apolitical research. Social scientists such as Dewey, Lynd, and Mannheim rejected the idea of producing social science that resembled natural science, particularly if it was to be value-free and apolitical (Solovey 2004). Others were content to let social science "ride on the coattails of natural science" (ibid). 
research leaves invisible the everyday work of producing knowledge in the context of macro-relations. Moreover, with its exclusive focus on sociology, it does not fully account for the ideological and political tensions felt across and within other disciplines than sociology.

I position CIHR, and the junior social scientists who apply to CIHR, within a larger politics of disciplines. Focusing on the power relations implicated in the inclusion of social science in a funding agency dominated by a medical science model, my research investigates the changes to certain types of social science that occur during interdisciplinary collaboration. Given that CIHR is part of a larger climate of 'interdisciplinarity,' which involves boundary-work and debates on the role of social science in nationally funded research, this paper asks - how do social scientists negotiate this? How do they alter or assert their values, and at what intellectual costs? My findings show that in the process of developing an application, junior social scientists doing qualitative health research reaffirm the boundaries between social science and natural science by erasing unique components of social science and by adopting what they perceive as characteristics of natural science. While not all interdisciplinary collaboration is the same, and while not all social scientists face similar difficulties, my research identifies the potential intellectual costs incurred by the trend to integrate social science under more dominant natural/biomedical science funding mandates.

\section{The Study}

\section{Method of inquiry}

Drawing from Dorothy Smith's (2005) work on institutional ethnography (IE), this research provides a unique lens into the process of making contemporary social science alongside interdisciplinary politics by looking at the specifics of creating funding applications. Institutional ethnography situates inquiry in the actual experiences and the actual doings of real people in the material world. The focus is on what they do, how they do it, and what guides and/or inhibits them in their doings. Using this as an entrance point to guide my research allows me to explore and discover which properties of particular social organization are present during the everyday processes of making of a CIHR application. From there, I focus on the outcome: the final application that was produced as qualitative social science graduate students negotiate intellectual and disciplinary boundaries. As such, this research goes beyond macro explanations of academic capitalism (i.e., Slaughter and Rhoades 2004) and funding 
fairness to explicate of how some social scientists produce knowledge in its early stages during the development of a funding application.

\section{The research project}

The findings presented in this paper come from seven interviews conducted in 2009-10 with social science graduate students at a large Canadian university who had applied or were in the process of applying to CIHR. Three informants were Master's students and four were doctoral candidates. Six were female, one male. All informants have been given a feminine pseudonym to protect anonymity. Four of the junior social scientists interviewed were currently in sociology, two in psychology, and one was trained in women's studies, although most had other social science training/backgrounds as well. These junior social scientists had specializations in areas that included Aboriginal studies/ research methods, critical theory, gender/women's and feminist studies, and public health. No preference was given to applicants who were successful in receiving funding over those who were not. The study focused solely on qualitative research applications, but quantitative or mixed methods based applications may experience some similar struggles during the application process.

Knowledgeable informants were recruited using flyers posted on campus as well as through snowball sampling where I contacted people I knew from the social science graduate student community. Recruitment posters sought "social scientists to volunteer in a research project who are Master's or PhD level graduate students and who have applied to CIHR in the past four years." The poster did not specifically seek out informants who had difficulty or trouble applying. Ethics approval was received through the University Human Research Ethics Board following the requirements of the Tri-Council Policy statement. The informants were both social scientists and students. They were in the process of being socialized into the broad traditions of social science as well as the specifics of their home discipline and had to navigate the demands, suggestions, and requirements of their supervisors and the academic institution they attended as well as their precarious financial situation. Disciplinary socialization occurred alongside CIHR's guidelines and requirements for "internationally accepted standards of scientific excellence" (CIHR).

\section{Interviews}

Informants were instructed to bring to the interview any materials relevant to their application to CIHR, and if possible, the various drafts of their application. Open-ended interviews lasting approximately 90 -minutes were conducted at a site of the informant's choosing such as campus 
offices or homes. The informants spoke openly about their experiences making an application, the activities involved in making it, and the difficulties they encountered during the process.

The objective of these interviews was to get the junior social scientists to "walk me through" their processes of making a social science research application for CIHR by focusing on the application itself, specifically the Project Summary, a one-page document specifying the details of the research project. In some cases, applicants brought in all the drafts of their application, and we went through each draft together. They read each draft aloud, starting with the first draft. If they only brought in the final draft, we would do the same process, only with the final draft. As they read their draft(s), I would stop them and ask them to discuss why certain information was included or excluded, why this was the case, and what it meant to them. As the interviews progressed, they became more comfortable explaining the choices involved in writing, rewriting, and developing the application without my asking. In the interviews involving multiple drafts, the informants noted what information was missing from later drafts, why it was missing, and what it meant to them that it was excluded.

\section{Analysis}

Interviews were transcribed and this narrative data was categorized in folders to organize the informants' experiences. For example, one folder was titled "work" and any information relating to a "work process" was entered, then organized again into different "work processes" such as "changing methods." I did not perform a content analysis of the textual applications, and my intent was not to "analyze" or to code any of the interview data, but rather to organize the experiences (rendered through interviews with the use of texts) so I could begin to write an account of making a CIHR application on the basis of what I learned from reading each folder containing collections of experiences.

Focusing on the development of the applications allowed me to discover how texts, such as applications, inscribe discourses and expectations and pass them onto sites of institutional action-how they coordinate institutional action, such as CIHR's goals and agendas, and how they create the actualities of institutions. According to Smith (2006), using texts in interviews allows researchers to "reach beyond the locally observable and discoverable into the translocal social relations and organization that permeate and control that local" (65). The CIHR application is a text that coordinates social scientists' actions, allowing me to discover the boundary-work that might be present during the process. This is not a textual analysis where I analyzed the content of the applications. Rather, the applications were a starting point to discuss the work of applying to CIHR. I view the application as an object that is intertwined with larger relations of ruling as well as larger structural and ideological 
conversations about disciplinary boundaries, demarcation, and science. The interviews exposed the broader relations and ideologies involved in the organization of the applicant's activities in terms of what can and cannot be done.

On the issue of generalizability and sample size, in an institutional ethnography, generalizability is not used in the traditional sense of the word. Rather, it is found to "lie in the abstract, general character of the "hooking up" phenomena under investigation" (Smith, Mykhalovskiy and Weatherbee 2006). The point is to draw an account of the social organization of a particular process, in this case of making an application for funding to CIHR, not of individual behaviours. My emphasis in this research is not on individual actors' decisions, but on the social organization of specific actions and what this represents.

\section{FindingS}

The most salient finding of this research is that key aspects of some kinds of social science (i.e., critical methods, feminism, creativity) are excluded from applications as junior social scientists employ their own or their supervisors' assumptions about what demarcates science from other forms of knowledge production to determine what should be included and excluded from their applications. In the Research Summary instructions, CIHR requests that applicants "include the specific hypothesis" and that "this summary should be written in general scientific language." Informants' narratives show struggles to frame their research in ways that successfully traverse the boundaries between natural science and social science. In what follows, I first highlight the intellectual costs of boundary-work for social science applications. I show what is left out of applications and why it is left out. Second, I emphasize how applicants accommodate science in attempts to make their research - in the words of one participant - more "sciency." These findings show the kind of politics of boundary-work which guides these qualitative junior social scientists' decisions on what will count as science in their applications to CIHR.

\section{Leaving critical strategies}

Informants expressed excitement with their initial research interests and some expressed a passion for critical theory and strategies. This passion and excitement contrasted with their disappointment at excluding critical theory from the final proposal. Informants experienced confusion when trying to include critical theory in applications, resulting in it's abandonment in the final draft. Critical strategies in social science imply a critique of some type; they recognize inequalities and injustices and often challenge taken-for-granted assumptions and understandings (Carroll 
2004). Because of this, they are often viewed as not 'objective' or 'value free.' Critical sociology and critical praxis are intrinsically oriented towards evaluation, advocacy, action, and are meant to "understand and enhance the basis of social transformation" (Sallah 1971, 137).

They do not presume an outcome, but rather begin from a problematic and emphasize the relationship between "critical social science and practical action," which has epistemological consequences (ibid,137). Advocating critical praxis, Mannheim (1936) notes, there are "activist elements in knowledge" (295 - 296) and the abandonment of political activism in social theory is based in assumptions surrounding "idealistic" conceptions of knowledge and from viewing this form of knowledge as "impure" (295 - 296). Though some scholars critique their "objectivity," critical theory and methods play a significant role in social science research. The decision to leave aside a critical approach was especially problematic for participant, Helen, who wanted to do critical theoretical work to rethink the social dimensions of health utilized by a dominant paradigm in health research. Her goal was to examine discrepancies between theory and health researchers' practice when they work to identify the social dimensions of health. Here, she expresses the tensions around leaving key aspects of her research design out of her application:

I didn't go into the [critical strategies] at all because I didn't see a point of going into that in any depth. I just said I would look at research and inequality and health... It was hard, I was like, should I stay vague? But by doing that, it gets rid of the really specific stuff about what I am actually doing, but I didn't think they would understand. My supervisor said to keep it understandable because you are writing for a medical audience... You can't even spin it. You feel like you already have a strike against you because you can't even use the language you're accustomed to. In a way, every word I was choosing I was like, who is going to read this? Are they even going to know what I'm talking about?

For Helen, a major struggle with her application was communicating critically guided social science to CIHR scientists, which resulted in the abandonment of this approach. Helen may have experienced a similar dilemma if she were applying to SSHRC because critical theory faces broader challenges to its legitimacy within social science as compared to empirical-analytic research. That said, Helen's particular decision to remove this language was a response to her perceptions of the specific medical audience she was writing for and advice she received regarding CIHR applications. This excerpt illustrates how Helen's decision was guided by her perception of what counts as medical science. She took the view that critical strategies have no place in a natural science paradigm and that biomedical audiences are unfamiliar with the traditions and 
methods of critical social science. This is demonstrated by Helen's concern with who would be reading the application and whether they would be familiar with this approach. Helen's comments expose the powerful role that the demarcation of science has on the development of research. Helen transformed her work into an applied, a-critical project to accommodate what she thought would be valued by CIHR.

\section{Leaving feminism and modifying gender}

Several informants expressed concern over their perceived inability to bring a feminist praxis into their application. For example, Leah's supervisor insisted she not use a feminist orientation in her application:

[My supervisor said] it was not part of CIHR. Don't use it. I was pretty taken aback by that, but I realize feminism is still not accepted in academic circles. It's one of those things. I wanted to get the funding, so I played the game. But it's also unfortunate that if I had chosen to keep [the feminist theory and praxis] in, I don't know how that would have affected their decision or not.

Leah's experience demonstrates the stigma that feminist work faces in science, and the anticipated consequences of including feminist theory and praxis in an application to CIHR. For Leah and her supervisor, developing the strongest possible application for CIHR meant not including a feminist praxis. The removal of feminism from the application was part of Leah's approach to negotiating the boundary between science and other ways of knowing.

While Leah removed feminism from her work entirely, others modified how they included gender and represented women. Andrea felt that she had to focus her research on all women:

I was looking specifically at lower-income women but then [in the application], I said that it doesn't just benefit lower-income women, it benefits all women plus their families and anyone who loves them! So basically all of society (laughs)! [I took] it away from just low-income women to make it benefit all women because you want to fund research that is going to make middle-class women happy. This felt to me like I was downplaying the experiences I wanted to forefront (low-income women's experiences) because they were the most marginalized experiences from within the data I was working from.

While CIHR does have an area dedicated to gender and health called The Institute of Gender and Health (IGH), including gender in one's research is not synonymous with using feminist epistemologies or methodologies. Women are commonly treated as a homogenous group and a 
single analytic category in Western scholarship, with a focus primarily on the experiences of white, middle class women. This leads to universal and hegemonic theories of women's oppression as well as the development of white/middle class perspectives on women's problems, which neglects and misrepresents many women's experiences. In response to this treatment of women, feminist scholarship has worked to address the interconnectedness of various inequalities in an 'integrative', non-additive way (Glenn 1999). This approach emphasizes that women experience race, gender, and class as simultaneously linked, requiring feminist approaches such as multiracial feminism (Zinn and Dill 1996; Collins 2000) and intersectionality (Crenshaw 1991), arguably political methodologies where knowledge is often developed from lived experiences (Naples 2013). These theoretical approaches require distinct methodologies to address the complexity of inequalities. Categorizing types of intersectional research, Choo and Ferree (2010) identify group-centred, process-centred, and system-centred approaches. They state that, "[t]he first emphasizes including multiply-marginalized groups in the content of the research; the latter two focus on explaining intersectional dynamics through the way that the analysis of the data is done" (130). McCall (2005) identifies three approaches to intersectional analysis, anticategorical, intercategorical, and intracategorical approaches, each producing different forms of substantive intersectional knowledge.

Andrea's research would have been submitted to the IGH. However, her narrative demonstrates the perceived pressure even within the IGH to position all women as a homogenous group. This approach neglects and misrepresents many women's experiences. Due to this highly problematic framing of women, Andrea's proposal ignored key tenets of intersectional feminist research, removing the possibility of explanations that could have revealed gendered health inequalities along the lines of class or race.

The treatment of women as a homogenous group situates Andrea's research as beneficial to a larger society, a move that she believes is more appealing to CIHR because it links more directly to public policy for the health of all women and Canadians, one of CIHR's goals. The consequence of this framing rendered invisible the perspectives and inequalities of the lower class women that Andrea sought to explore.

\section{Leaving creativity}

In the process of modifying their research, applicants expressed an inability to be creative and autonomous researchers while negotiating their 
qualitative social science traditions within CIHR. Joyce, a qualitative community-based researcher lamented:

It seems too rigid, this whole process. There is little flexibility, very little room for individual agency. As a researcher [who uses] different types of knowledge and methods I would have proposed something entirely different, like life histories, or monthly diary interviews, like very engaging with participants, and I didn't. I felt like a lot of my background is very devalued in this process. Had I applied to SSHRC, I would have applied differently and highlighted different things... [But with CIHR] I had no hope in getting funding if I pursued [my interests]... Doing communitybased research questions, you don't know what you will ask, or who it will be with. But with the way the application is structured, you need to [know this information].

Part of what makes social science knowledge construction unique is the ability to develop explanations that differ from those generated through the biomedical and natural sciences. In their research on the peer-review adjudication of research proposals, Guetzkow, Lamont, and Mallard (2004) argue that there are disciplinary differences in definitions of originality. The sciences "define originality as the production of new findings and new theories" while the humanities, history, and social science view originality:

As using a new approach, method, or data, studying a new topic and doing research in a under studied area, as well as producing new theories and findings... and in data used. For their part, social scientists mostly mentioned originality in method... stressing the use of an original approach, original theory, or the study of an original topic (191).

Social scientists often perceive creativity, or the discovery of new problems and the development of new ways to approach the social world as integral to the research process. For Joyce, creativity is the desire to use 'alternative' data collection techniques common in some qualitative social science research. Like Joyce, Andrea also felt inhibited in the inability to emphasize creativity in her research. This inhibition was triggered by the strict expectation to present research through a normal science paradigm and style.

I had to downplay artistic merit or reflexivity, or any kind of two-way relationship in interviewing, or anything else I would be doing. I had to maintain more objectivity... [The final product] was more conservative.

For Andrea, making an application 'scientific' meant enforcing the artificial separation between art, reflexivity, and research to demonstrate her 'absolute' objectivity as a researcher. This excerpt highlights her aware- 
ness of objective science as the ideal model for the CIHR application. Investigating the evaluation of qualitative research methods in the health sciences, Eakin and Mykhalovskiy (2003) emphasize that:

Most [evaluation] guidelines [in health sciences] are derivative of the modes of assessment developed by clinical epidemiologists as part of the promotion of evidence-based medicine (EBM). They are predominantly proceduralist in orientation, equating quality with the proper execution of research techniques... [which] tends to over-simplify and standardize the complex and non-formulaic nature of qualitative inquiry" (187).

For Joyce and Andrea, making their applications scientific meant downplaying alternative, 'creative,' research methods to appear valuefree and objective. It is important to note that the alternative methods desired by these junior social scientists should not be taken imply that their research would be subjective or biased, which is a common assumption in the evaluation of qualitative research (Eakin and Mykhalovskiy 2003,189). Harding (1991) argues that socially situated knowledge and standpoint epistemologies require a strong objectivity that moves beyond the ideal for value-neutral science and absolute objectivity. Harding questions whether it is necessary or even possible to achieve the type of objectivity in knowledge production that is the goal of the natural sciences.

\section{Accommodating "science"}

The previous section focused on the erasure of some aspects of qualitative, critical, and feminist social science that occurred during the application process as junior social scientists grappled with the demarcation of science. This may not occur for all social scientists, such as social epidemiologists, who may have less difficulty with the procedural approach to conducting research. In this section, I highlight additions and adaptations made to applications to accommodate CIHR's request for general scientific language and the inclusion of a hypothesis.

\section{Changing and fitting methods}

Bourdieu (2004) argued that scientific "fields" have dominant and subordinate positions, and that some actors hold more scientific authority to influence the idea of "good science" (Bourdieu 2004; Albert, Laberge, and McGuire 2012). While CIHR does not explicitly state a methodological preference, it does request "internationally accepted standards of scientific excellence." This request was perceived by the applicants

5. Albert et al. (2009) argue that "scientific excellence" is aligned with "objectivist-type of approach and epistemologies that predominate in health research (usually rooted in clinical epidemiology)" (182). 
to contain specific expectations for research design. The applicants all expressed some degree of concern over the treatment of their preferred methods by CIHR's Peer Review Committees. Regardless of what scientific authorities and notions of 'good science' may have actually been present within CIHR, applicants and their supervisors approached the applications with a narrow understanding of what constitutes legitimate science. This understanding caused them to alter their research methods in ways that were often inappropriate for the informant's research groups and populations. Informants articulated insecurity in their proposed methods, and two informants expressed feeling "unethical" in their research practices. Sally, who conducts community-based Aboriginal research, outlines her struggle to make a style of research that was developed progressively with the community sound concrete.

I said [in the application that] I was going to develop the core part of the measure on my own based on lit review and different outcome measures based on other info, and then I would go to the partner with that first part and we would develop the second part together. What's happening now [that I've started the research] is I've got my community partner and we're in discussions about what program I'm going to look at... What I envision is that I will collect info from them about what are their goals, what are their objectives of the program, and then I will speak to the program participants and get their goals and their objectives for the program, then from these key informants develop a measure that will be able to assess or investigate those goals and objectives. [Then,] go from there.

Ideally, Sally's research and its goals were to be developed with community involvement from the very start. Community-based research is a controversial research strategy partly because it involves the participation of non-academic stakeholders, and it may receive criticism even in social science evaluation, such as in SSHRC. However, Sally was very aware of the difficulty in making this method appropriate for CIHR. She stated:

I don't fit into [CIHR's] box, and I've tried to for the purpose of this [application]. I could have given a lot more information if [CIHR] would have been open to hearing about it... CIHR has Aboriginal health research guidelines and there's a lot of controversy about how those had been established and I know that within that, one of those [controversies is around] community consultation... That is how community-based research happens... Aboriginal research happens in that way I just described, but I feel like CIHR doesn't get that, and they want to see the science at work, the informed academic science at work. For someone doing communitybased research, developing a community partnership takes a long time... [What I've proposed] would be a more efficient way. 
By downplaying community consultation and by changing the stages at which and methods through which the community consultation would occur, Sally attempted to transform her community-based research into 'good' and 'efficient' science. During her interview, Sally mentioned that the first reviewer of her application critiqued her methods for not specifying the context within which the research would occur, as well as her under-articulation of expected outcomes. The second pointed out that the application requires a specific hypothesis, and that more details on the methods would be helpful. As is consistent with community-based research methods however, Sally's research, it's questions, and the program to be evaluated were to be developed during community consultation.

Adapting her methods to accommodate CIHR was also highly problematic for Cora, who wanted to stay true to Aboriginal research methods. In response to the colonizing practices of Western research programs, Aboriginal writers, scholars, and theorists have developed and continue to develop their own research paradigms and programs (Martin and Mirraboopa 2003; Smith 1999). Martin and Mirraboopa (2003) argue, "Indigenist research must centralise the core structures of Aboriginal ontology as a framework for research if it is to serve us well. Otherwise, it is western research done by Indigenous people" (206). Aboriginal methods look beyond 'fact-based' information to emphasize Aboriginal ways of knowing specific to Aboriginal ontology that emphasize "Entities of Land, Animals, Plants, Waterways, Skies, Climate and the Spiritual systems of Aboriginal groups" (Martin and Mirraboopa 2003, 209). In her ethnographic research with two groups of knowledge practitioners who work with clams, Kwakwaka'wakw First Nations (Native American) traditional marine harvesters and DFO government biologists, Marlor (2010) emphasizes how alternative, non-scientific ways of knowing are excluded because they do not employ standardized methods in the same way as traditional science.

Despite her desire to use Aboriginal research methods, Cora's final CIHR application aimed for legitimacy by emphasizing quantitative methods and standardized paper and pencil questionnaires. For Cora, this style of research was highly unethical and inappropriate for producing research with Aboriginal people. This change in research method exemplified the very colonizing research practices that she fought to avoid. 
One of the challenges for the study is to avoid reinforcing binary relationships between Aboriginal and non-Aboriginal... That was one of the things I felt was problematic when I was meeting with [my supervisor] was comparing the two groups. I just think that it is essentializing by saying Aboriginal people are doing this and non-Aboriginal people are doing that, you know? There are also cultural sensitivities. That was really important to me, just like having an Aboriginal perspective or pedagogy. It's very different than a Western research focus... Initially I wanted it to be more qualitative, but my supervisor told me to say that it was going to be both qualitative and quantitative, because that looks better... I think Aboriginal perspectives are very marginalized and they're not respected. They're not seen as real knowledge.

Cora's reluctance to accommodate the boundary of natural/biomedical science comes from her concern with colonizing research practices that are produced by standard methodological practices. Her concern is with the methodological and discursive construction of Aboriginal people as an 'other' in comparison to an implicit privileged and normative white reference group. Due to the marginalized nature of Aboriginal ways of knowing, Cora would likely be faced with questions of legitimacy applying to other funding agencies as well. However, Cora's account points to a process of making science - as opposed to making knowledge - when faced with an interdisciplinary organization dominated by the biomedical sciences that emphasizes the requirement for a specific and narrow type of 'scientific excellence.' This includes employing standardized tools and mixed methodologies over qualitative or Aboriginal research methods. Her narrative illuminates what methods are left out, and what research remains "undone" (Hess 2007) under this narrow view of 'good science.' Ironically, in changing her methods, Cora is reinforcing the boundary of what counts as legitimate research.

\section{Developing a hypothesis}

CIHR instructs applicants to clearly state their hypothesis, a major element of some types of science. A scientific hypothesis is "a supposition or proposed explanation" (Oxford 2010, 863). This request functions as boundary-work and privileges the types of scientific inquiry that can be stated as hypotheses. Social science research (and some forms of natural/ biological research) does not always involve a specific hypothesis as the goal of the research is not to provide an explanation of a phenomenon or to disprove or falsify a theory or a specific question. Much qualitative social science is exploratory and begins with research questions, not necessarily hypotheses, which evolve as the research progresses. Consequently, developing a hypothesis is not an appropriate request for 
many legitimate social science research agendas. Providing overall objectives and research questions is more common in some social science research proposals, but doing so risks confusing CIHR's reviewers regarding what the study is actually testing.

Joyce expressed this conflict between the need to formulate a hypothesis for the research proposal and the actual objectives of her social science research:

It was confusing because I initially had a specific hypothesis but didn't feel like it was necessary for this type of research. Like, I don't think my work boils down to a specific, it's more about the questions I'm asking. That is the nature of qualitative social science research. I kind of recognize [the guidelines] might be more aimed at clinical research, and I wondered at what point you have to follow instructions in this application, and at what point it didn't make sense for me to do that.

Likewise, Andrea found developing a hypothesis inappropriate for her project:

I had to develop a hypothesis, which seemed contrary to the inductive reasoning I wanted to use for my qualitative project. So, I needed to frame it in a deductive way... I needed to, I don't want to say fudge my project (laughs), but change my project in order to receive the funding in order to do my research.

These excerpts highlight how macro-level ideologies governing the requirements and characteristics of science influence knowledge construction at the micro level. CIHR successfully demarcated the boundaries of scientific research through the requirement for a hypothesis. While some applicants produced a hypothesis, others were not able to or refused to meet that requirement. Highlighting the importance of including clear population details, methods, and hypothesis in the application, Leah referred to the reviewers' comments:

I have my reviewers' comments and that was one of their critiques, was that I don't have a clear hypothesis and that 'the details on proposed sample population and methodology would have helped to clarify the nature of the study.' So I definitely lacked in that area, but I don't know the demographic of [my population]... Because of the ethical restraints I can't contact [my informants] before I do all this other stuff because it is not public knowledge who they are or what their background experience is. So I don't really know until I get ethical approval to contact them (Leah).

In this case, it could be that the reviewer meant that she did not have a clear 'overarching argument' - a common critique of research propos- 
als that may have occurred in an application to SSHRC as well. However, even if this is what the reviewer meant, her/his use of the word hypothesis highlights the slipperiness of communication between the disciplines.

With the expectation for a clear hypothesis, there is a very real danger of 'good' science being restricted to the hypothesis-testing model. This very narrow understanding of 'good science' threatens to exclude the richness and diversity of the social world alongside other modes of knowledge generation that are as scientific and objective as those used in the natural/biomedical sciences (see Harding 1991 on 'strong objectivity').

\section{Conclusion}

While this research focused on a small set of Canadian researchers, social scientists across a wide range of disciplines and nations face similar difficulties when interacting with interdisciplinary and funding institutions. Future research in this area would benefit from exploring the implications of CIHR's health funding mechanisms for researchers who are later in their career and from a wider variety of social science backgrounds and epistemological traditions. Furthermore, because research proposal development is a time of planning, future studies should explore whether the research proceeds as proposed.

This research on the boundary-work required by junior social scientists making qualitative applications to CIHR contributes to an ongoing conversation on how knowledge is altered by requirements of interdisciplinarity, changes to funding conditions, and conflicting academic values. It shows how the practices of researchers are shaped and constrained by the ideological relations at play in the interdisciplinary organization of CIHR and exposes the epistemological and methodological consequences of boundary-work and demarcation on social science research. The research also points out how junior researchers and their supervisors negotiated CIHR's definitions of what counts as science. To obtain funding for their research, the social scientists I interviewed necessarily engaged a narrow view of science and developed applications for CIHR that left behind certain ways of knowing (e.g., Aboriginal and feminist epistemologies) and made invisible certain populations (e.g., lowincome women). Ironically, this could lead to the mismanagement of the health outcomes for certain groups due to the exclusion of alternative epistemologies by social scientists developing their applications and by CIHR in adjudicating these applications. This is in direct contradiction to CIHR's mandate to produce the best health knowledge possible. 
Whether or not CIHR agrees, their commitment to 'internationally accepted standards of scientific excellence' coupled with their request for a hypothesis and general scientific language produces a hierarchy of knowledge production where qualitative social scientists feel they must alter their projects to fit within a very narrow model of 'good science.' In doing so, they erase many of the unique contributions that social sciences offer health related research. The 'hypothesis testing' model ignores the complexity of the social world and creates a social science that is devoid of critical strategies and theory, alternative and creative methods, and feminist praxis. This limits the ways in which researchers identify and address health inequities. The result is the creation of new intellectual boundary lines where qualitative social science aims to look more like biomedical science in scientifically dominated interdisciplinary organizations.

Attention must be paid to the power struggles within and between academic communities, especially when engaging in interdisciplinary endeavours, if the benefits of social science health research are to be realized. There is a need to reconsider the privilege that natural science has been given in CIHR applications and how CIHR and social scientists might reduce the erasure or alteration of social science that occurs at the earliest stage of applications. If social science health research is to remain under the funding mandate of CIHR, and if social scientists are to contribute to the health of Canadians and to the reduction of health inequities in interdisciplinary settings, CIHR must better integrate and legitimize alternative pathways to producing knowledge by broadening and making more inclusive the boundaries of what it considers 'excellent research.'

\section{ACKNOWLedgments}

I would like to thank William Carroll and Dorothy Smith for their intellectual guidance and insight during the research process. I thank Hae Yeon Choo, Zaheer Baber, Neil McLaughlin, Catherine Cheng, Louise Birdsell-Bauer, Linda Derksen, and Salina Abji for their very helpful and discerning comments on earlier drafts of this paper. I would also like to thank Kevin Haggerty and the four anonymous reviewers of the Canadian Journal of Sociology for their valuable comments on the previous version of this paper. I also thank all of the participants in this study who kindly spoke with me about their experiences. All errors remain mine. This research received no specific grant from any funding agency in the public, commercial, or not-for-profit sectors. 


\section{REFERENCES}

Abbott, Andrew. 2001. Chaos of Disciplines. Chicago, IL: University of Chicago Press.

Albert, Mathieu, Suzanne Laberge, Brian D. Hodges, Glenn Regehr, and Lorelei Lingard. 2008. Biomedical scientists' perception of the social sciences in health research. Social Science \& Medicine 66(12): 2520-2531.

Albert, Mathieu, Suzanne Laberge, and Brian D. Hodges. 2009. Boundary-work in the health research field: Biomedical and clinician scientists' perceptions of social science research. Minerva 47(2): 171-194.

Albert, Mathieu, Suzanne Laberge, and Wendy McGuire. 2012. Criteria for assessing quality in academic research: The views of biomedical scientists, clinical scientists and social scientists. Higher Education 64(5): 661-676.

Apostel, Leo, Guy Berger, Briggs, and Guy Michaud (Eds.). 1972. Interdisciplinarity. Paris: OECD.

Bachrach, Christine A., and Ronald P. Abeles. 2004. Social science and health research: Growth at the National Institutes of Health. Journal Information 94(1): 22-28.

Bernier, Nicole F. 2005. Integrating political science into health sciences. In Canadian Institutes of Health Research. The Social Sciences and Humanities in Health Research 124-125. Ottawa: CIHR.

Bourdieu, Pierre. 2004 [2001]. Science of Science and Reflexivity (trans: Richard Nice). Cambridge: Polity Press.

Braithwaite, John. 2005. For public social science. The British Journal of Sociology 56(3): 345-353.

Brint, Steven. 2005. Creating the future: 'New directions' in American research universities. Minerva 43(1): 23-50.

Carroll, William. K. (Ed.). 2004. Critical Strategies for Social Research. Toronto, ON: Canadian Scholars' Press.

Carrier, Martin. 2010. Research under pressure: Methodological features of commercialized science. In The Commodification of Academic Research, edited by H. Redder, 159-186. Pittsburgh, PA: University of Pittsburgh Press.

Choo, Hae Yeon, and Myra Marx Ferree. 2010. Practicing intersectionality in sociological research: A critical analysis of inclusions, interactions, and institutions in the study of inequalities. Sociological Theory 28(2): 129149.

CIHR. 2000. Canadian Institutes of Health Research Act. (S.C. 2000, c. 6). Current to May 1, 2014. Last amended on June 29, 2012. Access date: May 11, 2014 from http://laws.justice.gc.ca/PDF/C-18.1.pdf.

CIHR. 2013. Peer Review Committee Membership List. Access date: November 2, 2013 from http://www.cihr-irsc.gc.ca/e/39399.html.

Collins, Patricia, H. 2000. Black Feminist Thought. New York, NY: Routledge. 
Coulter, Kimberly. 2008. The NSF's 'cool' project: A charrette assesses interdisciplinary graduate education, with surprising results. Global Higher Ed Access date, November 4, 2013. http://globalhighered.wordpress. com/2008/03/21/the-nsf's-cool-project-a-charrette-assesses-interdisciplinary-graduate-education-with-surprising-results/

Crenshaw, Kimberle. 1991. Mapping the margins: Intersectionality, identity politics, and violence against women of color. Stanford Law Review 43(6): 1241-1299.

De Villiers, Jessica. 2005. Integrating the techniques of linguistic discourse into health sciences. In The Social Sciences and Humanities in Health Research, ed. Canadian Institutes of Health Research, 122-123. Ottawa: CIHR.

Eakin, Joan M., and Eric Mykhalovskiy. 2003. Reframing the evaluation of qualitative health research: Reflections on a review of appraisal guidelines in the health sciences. Journal of Evaluation in Clinical Practice, 9(2): 187-194.

Etzkowitz, Henry. 1998. The norms of entrepreneurial science: Cognitive effects of the new university-industry linkages. Research Policy 27(8): 823-833.

Frodeman, Robert, Julie T. Klein, and Carl Mitcham. (Eds.). 2010. The Oxford Handbook of Interdisciplinarity. New York, NY: Oxford University Press.

Gieryn, Thomas. F. 1983. Boundary-work and the demarcation of science from non-science: Strains and interests in professional ideologies of scientists. American Sociological Review 48(6): 781-795.

Glenn, Evelyn Nakano. 1999. The social construction and institutionalization of gender and race: An integrative framework. In ReVisioning Gender, edited by M.M. Ferree, J. Lorber, and B.B. Hess, 3-35. Thousand Oaks, CA: Sage.

Gross, Matthias. 2007. The unknown in process: Dynamic connections of ignorance, non-knowledge, and related concepts. Current Sociology 55:742759 .

Guetzkow, Joshua, Michèle Lamont, and Grégoire Mallard. 2004. What is originality in the humanities and the social sciences? American Sociological Review 69(2): 190-212.

Hacking, Ian. 2004. The complacent disciplinarian. Interdisciplines (online seminar). Access date: November 4, 2013. http://www.interdisciplines.org/ medias/confs/archives/archive_3.pdf.

Harding, Sandra. 1991. Whose Science? Whose Knowledge? Thinking From Women's Lives. Ithaca, NY: Cornell University Press.

Heintz, Christophe, and Gloria Origgi. 2004. Rethinking interdisciplinarity: Emergent issues. Interdisciplines (online seminar). Access date: November 4, 2013. http://www.interdisciplines.org/medias/confs/archives/ archive_3.pdf 
Hess, David. 2007. Alternative Pathways In Science And Industry. Cambridge: MIT Press.

Jacobs, Jerry. 2009. Interdisciplinary hype. The Chronicle of Higher Education 56(14): B4-B5.

Jacobs, Jerry. A. 2014. In Defense of Disciplines. Chicago, IL: University of Chicago Press.

Jacobs, Jerry. A., and Scott Frickel. 2009. Interdisciplinarity: A critical assessment. Annual Review of Sociology 35, 43-65.

Knorr-Cetina, Karin. 1999. Epistemic Cultures. Cambridge, MA: Harvard University Press.

Lamont, Michèle. 2009. How professors think. Cambridge, MA: Harvard University Press.

Laudel, Grit. 2006. The art of getting funded: How scientists adapt to their funding conditions. Science and Public Policy 33(7): 489-504.

Lyall, Catherine, Ann Bruce, Joyce Tait, and Laura Meagher. 2011. Interdisciplinary Research Journeys. New York, NY: Bloomsbury.

Mannheim, Karl. 1936. Ideology and Utopia. New York, NY: Harvest.

Marlor, Chantelle. 2010. Bureaucracy, democracy and exclusion: Why indigenous knowledge holders have a hard time being taken seriously. Qualitative Sociology 33(4): 513-531.

Martin, Karen, and Booran Mirraboopa. 2003. Ways of knowing, being and doing: A theoretical framework and methods for indigenous and Indigenist research. Journal of Australian Studies 27(76): 203-214.

McCall, Leslie. 2005. The complexity of intersectionality. Signs 30(3): 17711800 .

Morris, Norma. 2000. Science policy in action: Policy and the researcher. Minerva 38(4): 425-451.

Morse, Janice. M. 2006. It is time to revise the Cochrane criteria. Qualitative Health Research 16(3): 315-317.

Naples, Nancy A. 2013. Sustaining democracy: Localization, globalization, and feminist praxis. Sociological Forum 28(4): 657-681.

NIH-National Institutes of Health. 2007. NIH roadmap for medical research. http://nihroadmap.nih.gov/.

O'Rourke, Michael, Stephen Crowley, Sanford D. Eigenbrode, and J. D. Wulfhorst, eds. 2014. Enhancing Communication \& Collaboration in Interdisciplinary Research. Thousand Oaks, CA: Sage.

Oxford. 2010. Oxford Dictionary of English. New York, NY: Oxford University Press.

Prainsack, Barbara, Mette N. Svendsen, Lene Koch, Kathryn Ehrich. 2010. How do we collaborate? Social science researchers' experiences of multidisciplinarity in biomedical settings. BioSocieties 5(2): 278-286. 
Raphael, Dennis. 2011. Mainstream media and the social determinants of health in Canada: Is it time to call it a day? Health Promotion International, 26(2): 220-229.

Repko, Allen F., ed. 2012. Interdisciplinary research. $2^{\text {nd }}$ ed. Thousand Oaks, California: Sage.

Sallah, David L. 1971. Critical theory and critical sociology: The second synthesis. Sociological Inquiry 43(2): 131-140.

Seddon, Toby. 2013. Regulating health: Transcending disciplinary boundaries. Health Care Analysis 21(1): 43-53.

Slaughter, Sheila. 2004. Academic Capitalism and the New Economy. Baltimore, MD: JHU Press.

Smith, Dorothy E. 2005. Institutional Ethnography: A Sociology for People. Lanham, MD: Altamira Press.

Smith, Dorothy E. 2006. Incorporating texts into ethnographic practice. In Institutional Ethnography as Practice, edited by D. Smith, 65-88. Lanham, MD: Rowman \& Littlefield Publishers.

Smith, George W., Eric Mykhalovskiy, and Douglas Weatherbee. 2006. A research proposal. In Institutional Ethnography as Practice, edited by D. Smith, 165-80. Lanham, MD: Rowman \& Littlefield Publishers.

Smith, Linda Tuhiwai. 1999. Decolonizing methodologies. New York, NY: Zed books.

Solovey, Mark. 2004. Riding natural scientists' coattails onto the endless frontier: The SSRC and the quest for scientific legitimacy. Journal of the History of the Behavioral Sciences 40(4): 393-422.

Subramaniam, Mangala, Robert Perrucci, and David Whitlock. 2014. Intellectual closure: A theoretical framework linking knowledge, power, and the corporate university. Critical Sociology 40(3): 411-430.

Szostak, Rick. 2012. The interdisciplinary research process. In Case Studies in Interdisciplinary Research, edited by A.F. Repko, W.H. Newell, and R. Szostak, 3-20. Thousand Oaks, CA: Sage.

Zinn, Maxine Baca, and Bonnie Thornton Dill. 1996. Theorizing difference from multiracial feminism. Feminist Studies 22(2): 321-331.

Katelin Albert is a PhD candidate in Sociology at the University of Toronto. This research grew out of her Master's thesis on social science and CIHR, at the University of Victoria. Her current dissertation research centers on role of health technologies, in the case of the Human Papillomaviris (HPV) vaccine, in constructing understandings of girls' sexuality in Canada.

katelin.albert@mail.utoronto.ca 